\title{
RESTRIÇÕES À PUBLICIDAdE E PROMOÇÃO DO TABACO E A LIBERDADE DE EXPRESSÃo. CoNFlito DE DIREITOS?
}

\author{
FREEDOM OF EXPRESSION AND THE REGULATION OF TOBACCO \\ ADVERTISING AND PROMOTION. RIGHTS IN TENSION?
}

\author{
Oscar Cabrera* \\ Paula Avila Guillén** \\ Juan Carballo***
}

\section{RESUMO}

A Convenção-Quadro para o Controle do Tabaco (CQCT), da Organização Mundial da Saúde, tratado internacional com crescentes conexões com o direito internacional de direitos humanos, estabelece políticas de controle do tabaco que são recomendáveis. Entre elas destacam-se a proibição absoluta da publicidade e da promoção de produtos do tabaco. Até o presente momento essas medidas tiveram limitada aceitação em nível global, havendo poucos países que as implementaram. Do mesmo modo, embora haja diferentes casos judiciais que vinculam a regulação da publicidade e a promoção com a liberdade de expressão, há poucos antecedentes que discutem expressamente uma proibição total. A recente decisão da Corte Constitucional da Colômbia a esse respeito permite fundamentar uma posição que vincula a publicidade e a promoção de tabaco com as liberdades comerciais, mais do que com a liberdade de expressão. Essa

(*) Mestre em Direito e Políticas da Saúde, University of Toronto (Canadá); Graduado em Direito, Universidad Católica Andrés Bello (Venezuela). Diretor, Instituto O'Neill para o Direito da Saúde Nacional e Global, Georgetown University (Estados Unidos). Washington/Estados Unidos. E-mail: cabrera@law.georgetown.edu.

$\left({ }^{* *}\right)$ Mestre em Direito Internacional de Direitos Humanos, American University (Estados Unidos); Graduada em Direito, Universidad de Los Andes (Colômbia). Asssociada, Instituto O'Neill para o Direito da Saúde Nacional e Global, Georgetown University (Estados Unidos). Washington/Estados Unidos. E-mail: pa390@law.georgetown.edu.

${ }^{(* *)}$ Doutorando em Direito e Ciências Sociais, Universidad Nacional de Córdoba (Argentina); Mestre em Direito, Georgetown University (Estados Unidos); Graduado em Direito, Universidad Nacional de Córdoba (Argentina). Washington/Estados Unidos. E-mail: jmc327@law.georgetown.edu.

Texto recebido em 26.06.12. Revisado em 18.12.12. Aprovado em 24.12.12. 
diferenciação confere a possibilidade de estabelecer restrições mais estritas, como uma proibição total de publicidade e promoção, seguindo a CQCT. Ante as graves consequências geradas pela epidemia de tabagismo no mundo e considerando o papel-chave da publicidade e da promoção do tabaco em sua propagação, essas políticas se justificam como respostas exigidas no marco das obrigações derivadas do direito humano à saúde.

\section{Palavras-chave:}

Convenção-Quadro para o Controle do Tabaco (CQCT); Direito Humano à Saúde; Liberdades Comerciais; Publicidade e Promoção de Tabaco; Tabagismo.

\section{ABSTRACT}

The World Health Organization's Framework Convention on Tobacco Control (FCTC), an international treaty whose application has been leading to greater connections to international human rights law, establishes recommended tobacco-control policies. Highlighted among these policies is the absolute prohibition of tobacco product advertising and promotion. Thus far, this measure has received a limited level of acceptance at the global scale, with only a few countries implementing the recommendation. Likewise, although there are various court cases that establish a connection between freedom of expression and the regulation of tobacco advertising and promotion, few precedents expressly discuss an absolute ban. A recent decision by the Constitutional Court of Colombia regarding this very issue supports the view that tobacco advertising and promotion are more appropriately linked to commercial liberty, rather than freedom of expression. This distinction allows for the possibility of establishing stricter regulations, such as absolute bans on advertising and promotion, in line with the FCTC. Given the grave global consequences generated by the tobacco epidemic, these policies are justified because they fall within the framework of the necessary responses to the obligations derived from the human right to health.

\section{Keywords:}

Commercial Freedoms; Framework Convention on Tobacco Control; Human Right to Health; Tobacco Advertisement and Promotion; Tobacco Epidemics. 


\section{INTRODUÇÃO}

De acordo com a Organização Mundial da Saúde (OMS), morrem cerca de seis milhões de pessoas por ano em consequência da epidemia de tabagismo, sendo $80 \%$ dessas mortes nos países em desenvolvimento. O tabagismo é a causa principal da morte previsível em todo o mundo e, se for mantida a tendência atual, o tabaco matará mais de oito milhões de pessoas no ano de 2030. Se não forem adotadas medidas de controle, o tabaco poderá matar, no decorrer do século 21 , um bilhão de pessoas ou mais ${ }^{(1)}$.

Para responder a essa epidemia global, a Convenção-Quadro para o Controle do Tabaco(2) (CQCT) da OMS foi adotada em 21 de maio de 2003 pela Assembleia Mundial da Saúde e entrou em vigor em 27 de fevereiro de 2005. Atualmente essa Convenção conta com 177 Estados-Partes e se consolida como a principal ferramenta para o desenvolvimento de políticas efetivas de controle, tanto em nível doméstico como em ações de cooperação internacional. A par disso, a CQCT está em um processo de crescente consagração como um padrão para aplicação concreta da obrigação de direitos humanos de proteger o direito à saúde. A CQCT estabelece uma série de medidas obrigatórias que buscam reduzir tanto a demanda como a oferta de produtos de tabaco. Entre as primeiras e tendo em vista este artigo, destacamos a regulamentação que se enfoca num ponto-chave para a própria existência da epidemia do tabagismo: as estratégias de comercialização que promovem o consumo de tabaco.

Como se verá com mais pormenores logo adiante, através da publicidade, a promoção e o patrocínio de produtos de tabaco, a indústria tabagista incrementa as taxas de consumo com a consequente afetação da saúde pública. Por isso, as agências reguladoras enfrentam a necessidade de intervir nessas atividades, limitando o tipo de ações que podem ser levadas a cabo para promover uma atividade que comprovadamente afeta severamente a saúde. O extenso Art. 13 da CQCT regula tais ações estabelecendo como princípio geral a obrigação dos Estados-Partes de impor uma proibição total de toda forma de publicidade, promoção e patrocínio do tabaco. A par disso, e como se analisará mais adiante, prevê a possibilidade de estabelecer proibições parciais.

O presente artigo está focado na discussão sobre a viabilidade de estabelecer uma proibição absoluta da publicidade e promoção de produtos de tabaco a partir de uma perspectiva de direitos humanos que assegure a razoabilidade de possíveis limitações ao exercício de certos direitos e que ao mesmo tempo

(1) ORGANIZACIÓN MUNDIAL DE LA SALUD. Report on the global tobacco epidemic. Warning about the dangers of tobacco, 2011. p. 8. Disponível em: <http://www.who.int/tobacco/global_report/2011/ exec_summary/en/index.html>. Acesso em: 28 jan. 2013.

(2) ALIANÇA DE CONTROLE DO TABAGISMO. Convenção-Quadro para Controle do Tabaco. Disponível em: <http://actbr.org.br/pdfs/CQCT.pdf>. Acesso em: 22 jan. 2013. 
busque a máxima proteção possível dos diversos direitos em jogo ${ }^{(3)}$. Seria esse tipo de política violador de liberdades individuais, como é o caso da liberdade de expressão? Tendo em vista o conjunto de ações que se busca regulamentar e a magnitude da epidemia de tabagismo, sustentamos neste artigo que é possível estabelecer uma regulamentação como a proibição total de publicidade e promoção de produtos de tabaco desde uma perspectiva de direitos humanos. Argumentamos que esse tipo de medida não afetaria o direito humano à liberdade de expressão. Entendemos que, além das dificuldades para distinguir claramente os diferentes tipos de discurso na realidade, a publicidade se encontra mais vinculada às liberdades comerciais do que à liberdade de expressão. Por isso, é passível de maiores restrições, as quais, por pressuposto, deverão superar as correspondentes avaliações de razoabilidade e proporcionalidade. No caso concreto da publicidade e da promoção de produtos do tabaco e tendo em conta os efeitos negativos das estratégias de marketing na saúde pública, entendemos que a partir de uma perspectiva de direitos humanos se justifica uma restrição absoluta do direito de dar publicidade a produtos do tabaco.

Começa-se, neste trabalho, por fazer uma breve referência à CQCT e sua vinculação com tratados de direitos humanos, atentos à sua importância para o desenvolvimento de políticas de controle e especialmente com respeito à discussão das políticas de regulamentação da publicidade e promoção do tabaco. Posteriormente se analisará o impacto das estratégias de marketing da indústria tabagista nas atuais perspectivas da epidemia do tabagismo. Em seguida serão analisadas as medidas estabelecidas na CQCT com relação à publicidade e promoção de produtos de tabaco, com uma breve referência à recepção da legislação a ela relativa. Em continuação se dará especial atenção a uma recente decisão da Corte Constitucional da Colômbia que tem por foco, justamente, a discussão sobre a constitucionalidade de uma medida como a proibição total da publicidade e promoção de produtos do tabaco. Além disso, serão analisadas outras decisões com diferentes direcionamentos nessa discussão. Finalmente, concluir-se-á apresentando argumentos que fundamentam a tese antes sustentada: a partir de uma perspectiva de direitos humanos é possível justificar uma medida como a proibição de publicidade e promoção de produtos de tabaco.

\section{A CONVENÇÃO-QUADRO PARA O CONTROLE DO TABACO}

Como se argumentou anteriormente, a CQCT surgiu como resposta à forte ameaça que significa a epidemia de tabaco em nível mundial. Desde sua

(3) De acordo com o Departamento do Alto Comissariado das Nações Unidas para os Direitos Humanos, "num enfoque de direitos humanos, os planos, as políticas e os processos de desenvolvimento estão vinculados a um sistema de direitos e dos correspondentes deveres estabelecidos pelo direito internacional" (ALTO COMISSARIADO DE NACIONES UNIDAS PARA LOS DERECHOS HUMANOS. Preguntas frecuentes sobreelo enfoque de derechos humanos en la cooperación para el desarrollo. Nueva York; Ginebra, 2006. p. 15). 
negociação e entrada em vigor, a CQCT foi adquirindo um papel preponderante no desenvolvimento de políticas públicas de controle do tabaco.

Uma característica saliente da CQCT é sua estreita vinculação com tratados de direitos humanos ${ }^{(4)}$. No próprio preâmbulo do documento, faz-se a conexão com instrumentos tais como o Pacto Internacional de Direitos Econômicos, Sociais e Culturais ${ }^{(5)}$ (Pidesc), a Convenção sobre os Direitos da Criança ${ }^{(6)}$ ou a Convenção sobre a Eliminação de todas as Formas de Discriminação contra a Mulher(7). Mais adiante do que essa vinculação inicial, recentemente os mecanismos de monitoramento do sistema universal de proteção de direitos humanos utilizou a CQCT como uma ferramenta para interpretar em concreto a obrigação de proteger a saúde ${ }^{(8)}$. Como veremos, deve-se destacar que esse tipo de vinculação se fez inclusive com respeito a países que não ratificaram a adesão à CQCT, com o que a conexão com as obrigações de direitos humanos torna-se ainda mais forte.

A Comissão de Direitos Econômicos, Sociais e Culturais (Cdesc) ${ }^{(9)}$ fornece um primeiro exemplo dessa conexão entre a CQTC e as obrigações de direitos humanos. Em 2009, durante o exame periódico do Brasil, a Comissão recomendou ao governo brasileiro que, como Estado-Parte do Pidesc, tomasse medidas para reduzir o impacto do tabaco na população nos seguintes termos:

30. A Comissão toma nota com preocupação que no Estado-Parte continua sendo permitido incitar ao consumo de tabaco na publicidade e que, embora o consumo de produtos do tabaco esteja proibido nos espaços públicos, é permitido fumar em áreas especificamente designadas para esse fim. (...) A Comissão recomenda que o Estado-Parte adote medidas para proibir a promoção dos produtos

(4) CABRERA, Oscar A.; GOSTIN, Lawrence O. Human rights and the Framework Convention on Tobacco Control: mutually reinforcing systems. International Journal of Law in Context, v. 7, n. 3, p. 285-303, 2011.

(5) PACTO INTERNACIONAL DOS DIREITOS ECONÔMICOS, SOCIAIS E CULTURAIS. Disponível em: <http://www.oas.org/dil/port/1966\%20Pacto\%20Internacional\%20sobre\%20os\%20Direitos\%20 Econ\%C3\%B3micos,\%20Sociais\%20e\%20Culturais.pdf>. Acesso em: 27 jan. 2013.

(6) UNICEF. Convenção sobre os Direitos da Criança. Disponível em: <http://www.unicef.pt/docs/ pdf_publicacoes/convencao_direitos_crianca2004.pdf>. Acesso em: 27 jan. 2013.

(7) CONVENÇÃO SOBRE A ELIMINAÇÃO DE TODAS AS FORMAS DE DISCRIMINAÇÃO CONTRA A MULHER. Disponível em: <http://www.pge.sp.gov.br/centrodeestudos/bibliotecavirtual/ instrumentos/discrimulher.htm>. Acesso em: 27 jan. 2013.

(8) CABRERA, Oscar A.; MADRAZO, Alejandro. Human Rights as a Tool of Tobacco Control in Latin America. Salud Publica de Mexico, v. 52, p. 288-297, 2010.

(9) A Comissão de Direitos Econômicos, Sociais e Culturais (Cdesc) é órgão de especialistas independentes que supervisiona a aplicação do Pacto Internacional de Direitos Econômicos, Sociais e Culturais (Pidesc) por seus Estados-Partes. A Comissão foi implantada em virtude da resolução 1985/7, de 28 de maio de 1985, do Conselho Econômico e Social das Nações Unidas (Ecosoc) para desempenhar as funções de supervisão atribuídas a esse Conselho na parte IV do Pacto. A Comissão publica sua interpretação das disposições do Pacto em forma de observações gerais. COMITÉ DE DERECHOS ECONÓMICOS, SOCIALES Y CULTURALES. Disponível em: <www2. ohchr.org/spanish/bodies/cescr/index.htm>. Acesso em: 27 jan. 2013. 
de tabaco e aprove legislação para garantir que todos os espaços públicos fechados estejam completamente livres do tabaco. ${ }^{(10)}$ (grifos nossos)

Como fica evidente na observação e na recomendação correspondente, a Cdesc utiliza a CQCT como padrão para avaliar o cumprimento das obrigações que decorrem do tema do direito à saúde segundo o reconhecimento do Pidesc.

Como se antecipara, a vinculação se repete inclusive para países que não ratificaram a adesão à CQCT, como é o caso da Argentina. Em sua recente revisão do cumprimento de obrigações do Pidesc, a Cdesc afirmou o seguinte:

Preocupa a Comissão o alto nível de consumo de tabaco no Estado-Parte, especialmente entre as mulheres e os jovens (Art.12, §1). A Comissão recomenda ao Estado-Parte que ratifique e aplique a Convenção-Quadro da OMS para o Controle do Tabaco e que elabore políticas fiscais, de fixação de preços e de sensibilização da população que sejam eficazes para reduzir o consumo de tabaco, em particular entre as mulheres e os jovens. ${ }^{(11)}$ (grifos nossos)

Essa forte vinculação entre a CQTC e os tratados de direitos humanos levou, inclusive, a que ela seja interpretada como um tratado de direitos humanos em si mesma. Essa é a posição adotada pelo Tribunal Constitucional do Perú, que afirmou que a CQCT é um tratado de direitos humanos porque "busca proteger de maneira clara, expressa e direta o direito fundamental à proteção da saúde"(12). Aprofundando sua linha de pensamento e respondendo a possíveis críticas a essa posição, o tribunal explicou que:

a existência ou não de um tratado sobre direitos humanos não vem definida por um critério formal, como pode ser a análise se é o caso de um tratado que pela primeira vez reconhece um direito desse caráter, mas por um critério material, consistente em analisar se o tratado se ocupa diretamente de um direito humano, seja para reconhecê-lo pela primeira vez, seja para assumir obrigações orientadas à sua mais eficiente proteção. ${ }^{(13)}$

Sem entrar na discussão com respeito à sua natureza, para os fins deste trabalho, cremos importante ter presente a forte vinculação existente entre a CQCT e os tratados de direitos humanos e também o fato de que a CQCT se consolida como ferramenta para a interpretação em concreto da obrigação de proteger o direito humano à saúde.

(10) CESCR. Examen de los informes presentados por los Estados partes de conformidad con los Artículos 16 y 17 del Pacto. Observaciones Finales del Comité de Derechos Económicos, Sociales y Culturales: Brasil, 2009. p. 31. E/C.12/BRA/CO/2.

(11) CESCR. Examen de los informes presentados por los Estados partes de conformidad con los Artículos 16 y 17 del Pacto. Observaciones Finales del Comité de Derechos Económicos, Sociales y Culturales: Argentina, 2011. p. 23. E/C.12/ARG/CO/3.

(12) Tribunal Constitucional del Perú. Jaime Barco Rodas contra el Artículo $3^{\circ}$ de la ley N. 28705 - Ley general para la prevención y control de los riesgos del consumo de tabaco, proceso de inconstitucionalidad, Julio de 2011, párrafo 67.

(13) Tribunal Constitucional del Perú. Jaime Barco Rodas contra el Artículo $3^{\circ}$ de la ley N. 28705 - Ley general para la prevención y control de los riesgos del consumo de tabaco, proceso de inconstitucionalidad, Julio de 2011, párrafo 69. 


\section{A REGULAMENTAÇÃO DA PUBLICIDADE DE PRODUTOS DE TABACO}

\section{O PAPEL DAS ESTRATÉGIAS DE MARKETING PARA PROMOVER O CONSUMO DE PRODUTOS DE TABACO}

A epidemia de tabagismo tem muitas características únicas que não cabe desenvolver neste trabalho. Entretanto, é pertinente destacar que, diferentemente de outras epidemias, existe um setor que obtém benefícios econômicos diretos à medida que essa epidemia se agrava e que, por isso, desenvolve atividades tendentes a que ela aconteça. Como afirma Armando Peruga, o tabagismo tem como vetor primordial de expansão a indústria tabagista. ${ }^{(14)}$ Os altos índices de consumo são devidos às ações desta indústria: "a persistência de fumantes jovens em todo o mundo não é uma casualidade e se deve ao empenho das tabagistas em manter uma pepineira de consumidores que garantam o futuro do negócio".(15)

A indústria tabagista gasta bilhões de dólares atualmente para comercializar seus produtos e utiliza uma combinação de táticas de publicidade, promoção e patrocínio para influir diretamente sobre o consumo de tabaco e as atitudes relacionadas ao produto. A publicidade, promoção e patrocínio do tabaco apresentam o consumo de tabaco como algo habitual e glamuroso, contêm mensagens enganosas e errôneas, debilitam as campanhas de saúde pública e miram populações específicas, como mulheres, jovens e grupos minoritários. Segundo foi demonstrado por diversas investigações científicas ${ }^{(16)}$, os objetivos das estratégias de comercialização do tabaco orientadas aos consumidores são as seguintes: 1) recrutar novos consumidores de tabaco; 2) manter ou incrementar o consumo entre os consumidores atuais; 3 ) reduzir a predisposição dos consumidores de tabaco para deixar de fumar ; e 4) estimular os ex-fumantes para que comecem a consumir tabaco novamente.

Esses objetivos estão claramente relacionados com o impacto das estratégias de publicidade, promoção e patrocínio nas taxas de consumo, especialmente entre os jovens. Foi demonstrado que a comercialização de produtos de tabaco incrementa a iniciação do consumo de tabaco entre os jovens. ${ }^{(17)}$ A seguir serão citados alguns estudos que respaldam essas afirmações:

(14) PERUGA, Armando. El Convenio Marco Para el Control del Tabacco: respuesta a la globalización de una epidemia comunicada. Gaceta Sanitaria (online), v. 18, n. 5, p. 343-345,2004. Disponível em: $<$ http//scielo.php ?script=sciarttext\&pid=S0213-9112004000700001\&=iso $>$. Acesso em: 27 jan. 2013. (15) SOTO MAS, Francisco; XAVIER GARCIA LEON, Francisco. La industria tabaquera y la promoción del tabaquismo entre los menores y jóvenes : una revisión internacional. Gaceta Sanitaria (online), v. 23, n 5, p 448-457, 2009. Disponível em: <htpp://scielo.isciii.es/scielo.php ?script=sciarttext\&pid=S0213-91112009000500016\&lng=es\&nrm=iso >. Acesso em: 27 jan. 2013.

(16) ANDREWS, R. L.; FRANKE, G. R. The determinantes of cigarette consumption: a meta-analiysis. Journal of Public Policy and Marketing, v. 10, n. 1, p. 81-100, 1991.

(17) DIFRANZA, Joseph R. et al. Tobacco promotion and the initiation of tobacco use: assessing the evidence for causality. Pediatrics, v. 117, n. 6, p. e1237-e1248, 2006. 
- $\quad$ Revisão realizada em 2003 sobre nove estudos longitudinais que incluíram mais de 12 mil jovens concluiu que a publicidade e a promoção do tabaco aumentam a possibilidade de que os adolescentes comecem a fumar. ${ }^{(18)}$

- Estudo realizado entre 1999 e 2004 no Reino Unido determinou que, para cada modalidade do tabaco reconhecida por jovens, a probabilidade de iniciação do consumo de tabaco aumentava em $7 \% .^{(19)}$

- Estudo realizado na Espanha em 2004 determinou que a familiaridade com os anúncios publicitários locais sobre tabaco aumentou a probabilidade de iniciação no consumo de tabaco entre os jovens de 13 e 14 anos. ${ }^{(20)}$

- Estudo realizado nos Estados Unidos determinou que a publicidade nas lojas incrementou a probabilidade de iniciação no consumo de tabaco, enquanto a disponibilidade das promoções de vendas incrementou a probabilidade de que os jovens passem da experimentação ao consumo regular. ${ }^{(21)}$

Tal ação sistemática por parte da indústria tabagista implica um motivo de preocupação para os Estados e um chamado de atenção em vista de seu dever de assegurar uma adequada proteção do direito humano à saúde. A partir dessa perspectiva é pertinente considerar que a própria Cedesc afirmou, a respeito da obrigação de proteger, que o Estado tem uma obrigação de controlar terceiros que afetem negativamente esse direito, mencionando expressamente o caso da epidemia de tabaco. A Cedesc afirmou que:

as violações das obrigações de proteger se caracterizam pelo fato de que um Estado não adote todas as medidas necessárias para proteger, dentro de sua jurisdição, as pessoas contra as violações do direito à saúde por terceiros. Figuram nessa categoria omissões tais como (...) a não proteção dos consumidores e dos trabalhadores contra as práticas prejudiciais à sua saúde, como ocorre no caso de (...) não dissuadir a produção, a comercialização e o consumo de tabaco, estupefacientes e outras substâncias nocivas... (22) (grifo nosso)

(18) LOVATO C.; LINN G.; STEAD L. F.; BEST A. Impact of tobacco advertising and promotion on increasing adolescent smoking behaviors. Cohrane Database Syst Rev, n. 4, 2003. CD003439.

(19) MOODIE C.; MACKINTOSH A.M.; BROWN A.; HASTINGS G. Tobacco marketing awareness on youth smoking susceptibility and perceived prevalence before and after an advertising ban. European Journal of Public Health, v. 24, Mar 2008.

(20) LOPEZ, M. Luisa, et al. Impact of cigarette advertising on smoking behavior in Spanish adolescents as measured using recognition of billboard advertising. European Journal of Public Health, v. 14, n. 4, p. 428-432, 2004.

(21) SLATER S.; CHALOUPKA F.; WAKEFIELD M.; JOHNSTON L.; O'MALLEY P. The impact of retail cigarette marketing practices on youth smoking uptake. Archives of Pediatric and Adolescent Medicine, v. 161, n. 5, p. 440-445, 2007.

(22) COMITÉ DE DERECHOS ECONÔMICOS, SOCIALES Y CULTURALES. Comentario General N 14, Ginebra, 2000, E/C. 12/2000/4 (22 período de sessões). 
Em resumo, atendendo à existência digna de fé, de provas que demonstram que as ações da indústria tabagista em matéria de publicidade e promoção de tabaco impactam negativamente a saúde pública, um Estado com a obrigação de proteger o direito humano à saúde deveria desenvolver políticas para evitar esse agravo.

\section{A CONVENÇÃO-QUADRO PARA O CONTROLE DO TABACO E A REGULAMENTAÇÃO DA PUBLICIDADE}

O extenso Art. 13 da CQCT é o que regula a publicidade, promoção e patrocínio do tabaco. Sem entrar em detalhes sobre como implementar e monitorar as diferentes medidas estabelecidas neste artigo, serão transcritas em seguida as disposições mais relevantes quanto à discussão sobre a possibilidade ou não de implementar uma proibição absoluta da publicidade de produtos de tabaco.

1. As Partes reconhecem que uma proibição total da publicidade, da promoção $e$ do patrocínio reduzirá o consumo de produtos de tabaco.

2. Cada Parte, em conformidade com sua Constituição ou seus princípios constitucionais, procederá à proibição total de toda forma de publicidade, promoção e patrocínio do tabaco.(...)

3. A Parte que não esteja em condições de proceder a uma proibição total devido a disposições de sua Constituição ou seus princípios constitucionais imporá restrições a toda forma de publicidade, promoção e patrocínio do tabaco.(... (23)

Tanto com a finalidade de circunscrever conceitos para a presente análise como para apresentar cabalmente a regulamentação da CQCT, é oportuno citar as definições desse tratado, de alguns termos-chave para o presente artigo:

c) "publicidade e promoção do tabaco" é qualquer forma de comunicação, recomendação ou ação comercial com o objetivo, efeito ou provável efeito de promover, direta ou indiretamente, um produto do tabaco ou o seu consumo (...)

e) a "indústria tabagista" abarca os fabricantes, atacadistas e importadores de produtos de tabaco. ${ }^{(24)}$

Como se pode observar, tanto a definição de indústria tabagista como a de publicidade e promoção do tabaco são amplas e abrangentes.

Também se verifica que a regulamentação propõe, como primeira medida obrigatória, proibir de maneira absoluta a publicidade e a promoção de produtos de tabaco. Numa redação que busca favorecer a generalização do consenso, a CQCT atenuou essa obrigação para aqueles Estados que "não estejam em

(23) Art.13. ALIANÇA DE CONTROLE DO TABAGISMO. Convenção-Quadro para Controle do Tabaco. Disponível em: <http://actbr.org.br/pdfs/CQCT.pdf>. Acesso em: 22 jan. 2013.

(24) Art. $1^{\circ}$. ALIANÇA DE CONTROLE DO TABAGISMO. Convenção-Quadro para Controle do Tabaco. Disponível em: <http://actbr.org.br/pdfs/CQCT.pdf>. Acesso em: 22 jan. 2013. 
condições de proceder a uma proibição total devido às disposições de sua Constituição ou seus princípios constitucionais"(25). Proposta dessa forma, entende-se que só se pode justificar o não cumprimento da obrigação de estabelecer uma proibição total quando isso não seja permitido no quadro jurídico constitucional do Estado em questão.

Depois de estabelecer a obrigação genérica e a subsidiária, a CQCT especifica em maior medida como deveriam implementar-se essas proibições. Esse mesmo caminho é aprofundado pela diretriz relativa ao Art. 13 aprovada pela Conferência das Partes CQCT. No presente artigo e para os fins de análise da possibilidade de estabelecer uma proibição absoluta de publicidade e promoção de produtos de tabaco, deixaremos de lado as questões referentes à implementação dessas medidas para nos concentrar num plano de maior generalidade. Não obstante, na continuação se fará uma breve referência à efetividade das medidas propostas pela CQCT, porque esse ponto é relevante no momento de determinar a viabilidade de estabelecer uma proibição absoluta da publicidade e promoção.

\section{EFETIVIDADE DAS POLÍTICAS DE CONTROLE DE TABACO EM MATÉRIA DE PUBLICIDADE}

Mesmo tendo em conta que este trabalho não está focado em detalhes de implementação das medidas de proibição de publicidade e promoção de produtos de tabaco recomendada pela CQCT, consideramos importante fazer uma breve referência à sua efetividade. Como se viu nos tópicos anteriores, tanto a gravidade da epidemia de tabagismo como os esforços da indústria tabagista para incrementar as taxas de consumo exigem uma intervenção estatal, tendo em vista assegurar uma efetiva proteção do direito humano à saúde. Nesse contexto é válida uma interrogação sobre os efeitos das políticas propostas, já que esse será um ponto a ser considerado no momento de poder justificar a razoabilidade de uma restrição ampla de certos direitos.

A proibição total é a única medida efetiva que garante que nenhum jovem seja alcançado pelas estratégias publicitárias da indústria tabagista. Como dissemos anteriormente, a indústria gasta bilhões de dólares por ano para estender sua rede de marketing tanto quanto possível e assim atrair clientes jovens, que se reúnem em espaços familiares e de descontração (cinemas, internet, revistas de moda, concertos de música e encontros esportivos, por exemplo). (26) Por outro lado, está comprovado que as proibições totais da publicidade são eficientes não só para frear, mas também para diminuir o

(25) Art. 13.3. ALIANÇA DE CONTROLE DO TABAGISMO. Convenção-Quadro para Controle do Tabaco. Disponível em: <http://actbr.org.br/pdfs/CQCT.pdf>. Acesso em: 22 jan. 2013.

(26) ORGANIZACIÓN MUNDIAL DE LA SALUD. Report on the global tobacco epidemic. Warning about the dangers of tobacco, 2011, cit., p. 62. 
consumo de cigarros, com o consequente benefício para a saúde pública. ${ }^{(27)}$ Assim, por exemplo, um estudo realizado em 22 países de renda elevada concluiu que a proibição total da publicidade e promoção de cigarros reduziriam o consumo de tabaco em até $7,4 \%$. Individualmente, os países do estudo tiveram a experiência de uma diminuição no consumo de até $16 \%$ depois da introdução das proibições. ${ }^{(28)}$

As proibições parciais e os acordos voluntários tiveram pouco ou nenhum efeito sobre o nível de consumo de cigarros. Embora limitem as opções de canais de publicidade e promoção para a indústria tabagista, o total gasto em marketing permanece igual. Só as proibições totais podem vencer a rede de publicidade do tabaco. ${ }^{(29)} A$ indústria tem variadas formas de se colocar em contato com a juventude. As proibições parciais só conseguem que as empresas direcionem seus grandes recursos de uma tática promocional para outra. ${ }^{(30)}$

Esses estudos demonstram que, para os fins de uma proteção efetiva da saúde perante a epidemia de tabagismo e os esforços da indústria tabagista, a proibição absoluta de publicidade e promoção de tabaco surge como a única resposta adequada.

\section{REGULAMENTAÇÃO DA PUBLICIDADE E PROMOÇÃO DO TABACO NA ATUALIDADE}

\section{RECEPÇÃO LEGISLATIVA}

Na atualidade, aproximadamente 425 milhões de pessoas em 19 países, representando $6 \%$ da população mundial, estão protegidos de maneira integral contra as estratégias de marketing da indústria tabagista, o que significa um incremento de 80 milhões de pessoas em relação a 2008. A quase totalidade desses países são de baixa ou média renda. ${ }^{(31)}$

Isso se reflete no seguinte gráfico, extraído do último informe da OMS sobre tabagismo.

(27) WORLD BANK. Curbing the epidemic: governments and the economics of tobacco control. Washington, DC, 1999.

(28) SAFFER, H.; CHALOUPKA, F. The effect of tobacco advertising bans on tobacco consumption. Journal of Health Economicas, v. 19, p. 1117-1137, 2000.

(29) U.S. DEPARTMENT OF HEALTH AND HUMAN SERVICES, NATIONAL INSTITUTES OF HEALTH, NATIONAL CANCER INSTITUTE. The role of the media in promoting and reducing tobacco use. Tobacco Control Monograph No. 19. NIH Pub No. 07-6242, Bethesda, MD, 2008. Disponivel em: $<$ htpp//cancercontrol. Cancer.gov/tcrb/monographs/19/m19 complete pfd>. Acesso em: 27 jan. 1013. (30) HASTINGS, Gerard; MACFADYEN Lynn. Keep Smiling - No one's going to die. An analysis of internal documents from the tobacco industry's main UK advertising agencies. Clinical and Translational Research Commitee and the Tobacco Control Resource Center. Oct. 2000.

(31) ORGANIZACIÓN MUNDIAL DE LA SALUD. Report on the global tobacco epidemic. Warning about the dangers of tobacco, 2011, cit., p. 65. 


\section{Gráfico 1}

Bans on advertising, promotion and sponsorship

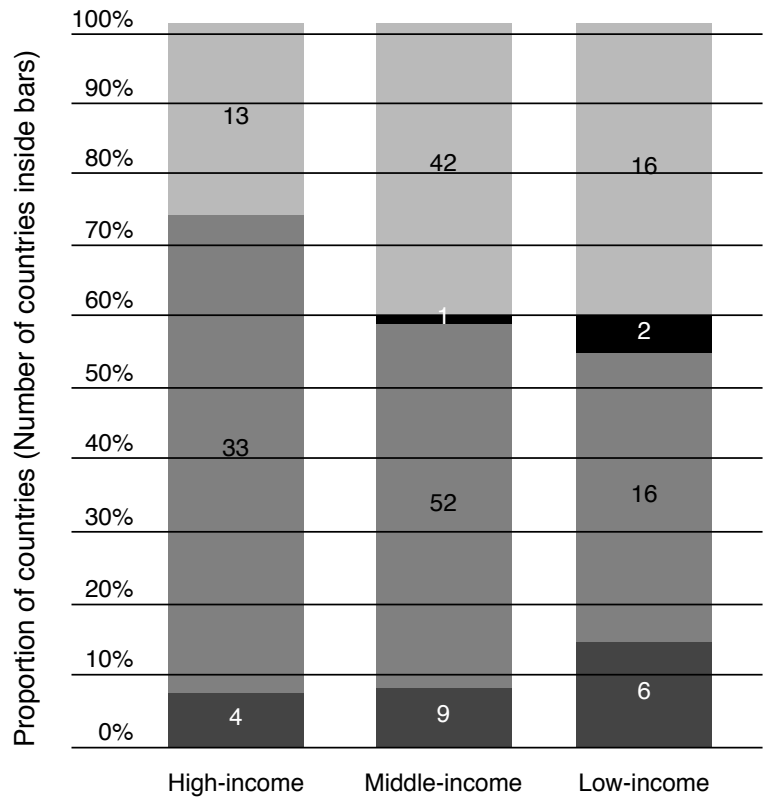

Data not reported

Complete

absence of ban, or ban that does not cover national TV, radio and print media

Ban on national TV, radio and print media only

Ban on national $\mathrm{TV}$, radio and print media as well as on some but not all other forms of direct and/or indirect advertising

Ban on all forms of direct and indirect advertising

Com respeito à região americana, só três países estabeleceram uma proibição absoluta de publicidade e promoção de produtos do tabaco: Panamá, Colômbia e Brasil. ${ }^{(32)}$

No Panamá, o Art. 14 da Lei $n^{\circ} 13$ de 2008 estabeleceu o seguinte:

Art. 14. Proíbe-se totalmente qualquer forma de publicidade, promoção e patrocínio do tabaco e de seus produtos, seja através de meios indiretos, seja de subliminais, dirigidas a menores ou maiores de idade. Igualmente, proíbe-se toda forma de publicidade, promoção e patrocínio transfronteiriço do tabaco e seus produtos que penetrem no território nacional. ${ }^{(33)}$

(32) No momento de elaboração deste trabalho, em 31 de maio de 2012, por ocasião da celebração do Dia Mundial sem Tabaco, o Ministério da Saúde do Uruguai apresentou um projeto de lei que proíbe de maneira absoluta a publicidade e promoção de produtos do tabaco. As discussões e os avanços desse projeto ficaram fora da análise do presente artigo.

(33) REPUBLICA DE PANAMÁ. ASAMBLEA NACIONAL. Ley $n^{\circ}$ 13, 24 de Enero de 2008. "Que adopta medidas para el control del tabaco y sus efectos nocivos en la salud". Disponível em: <http:/l www.asamblea.gob.pa/APPS/LEGISPAN/PDF_NORMAS/2000/2008/2008_557_1078.PDF>. Acesso em: 27 jan. 2013. 
Uma posição similar foi adotada pela Lei n 1335 de 2009 da Colômbia, que estabelece uma proibição absoluta através dos seguintes artigos:

Art. 14. Conteúdo nos meios de comunicação dirigidos ao público em geral. Nenhuma pessoa natural ou jurídica, de fato ou de direito, poderá fazer a promoção de produtos do tabaco em rádio, televisão, cine, meios escritos como boletins, periódicos, revistas ou qualquer documento de difusão em massa, produções teatrais ou outras apresentações ao vivo, apresentações musicais ao vivo ou gravadas, vídeo e filmes comerciais, discos compactos, discos de vídeo digital ou meios similares.(...)

Art. 15. Publicidade em painéis e similares. Proíbe-se a toda pessoa natural ou jurídica a afixação de painéis, cartazes, murais, folhetos ou similares móveis ou fixos relacionados com a promoção do tabaco e seus derivados.

Art. 16. Promoção. Proíbe-se toda forma de promoção de produtos de tabaco e seus derivados. ${ }^{(34)}$

O último país da região que se somou a essa reduzida lista foi o Brasil, através da Lei $n^{\circ} 12.546^{(35)}$, de dezembro de 2011, que acrescentou um artigo à Lei $n^{\circ} 9.294^{(36)}$, que modifica radicalmente o regime de publicidade. $O$ artigo em questão é o seguinte:

Art. $3^{\circ}$ É vedada, em todo o território nacional, a propaganda comercial de cigarros, cigarrilhas, charutos, cachimbos ou qualquer outro produto fumígeno, derivado ou não do tabaco, com exceção apenas da exposição dos referidos produtos nos locais de vendas, desde que acompanhada das cláusulas de advertência a que se referem os $\S \S 2^{\circ}$., $3^{\circ}$. e $4^{\circ}$. deste artigo e da respectiva tabela de preços, que deve incluir o preço mínimo de venda no varejo de cigarros classificados no código 2402.20.00 da Tipi, vigente à época, conforme estabelecido pelo Poder Executivo.

É importante destacar que até o momento o Panamá foi o único país que vedou de maneira expressa a exibição de produtos do tabaco, incluindo-a dentro da proibição integral de publicidade e promoção de produtos de tabaco. Essa regulamentação foi estabelecida através do Decreto Executivo $n^{\circ} 611^{(37)}$ do Ministério da Saúde, de junho de 2010, que dispõe que "a proibição total indicada no Art. 14 da Lei 13 de 2008 não permite a exibição dos produtos de tabaco e seus derivados nos dispensadores e vitrines ou qualquer outra prateleira situada

(34) SENADO DE LA REPÚBLICA DE COLOMBIA. Lei $n^{\circ}$ 1335, de 21 de julho de 2009. Disponível em: <http://www.secretariasenado.gov.co/senado/basedoc/ley/2009/ley_1335_2009.html>. Acesso em: 27 jan. 2013.

(35) BRASIL. Lei $n^{\circ} 12.456$, de 14 de dezembro de 2011 . “...altera as Leis $n^{\circ}(\ldots)$ 9.294, de 15 de julho de 1996 (...)". Disponível em: <http://www.planalto.gov.br/ccivil_03/_ato2011-2014/2011/lei//12546. $\mathrm{htm}>$. Acesso em: 27 jan. 2013.

(36) BRASIL. Lei n9.294, de 15 de julho de 1996. "Dispõe sobre as restrições ao uso e à propaganda de produtos fumígeros, bebidas alcoólicas, medicamentos, terapias e defensivos agrícolas, nos termos do $\S 4^{\circ}$ do art. 220 da Constituição Federal”. Disponível em: <http://www.planalto.gov.br/ ccivil_03/leis/L9294.htm>. Acesso em: 27 jan. 2013.

(37) REPUBLICA DE PANAMÁ. MINISTÉRIO DE LA SALUD. Decreto Ejecutivo $n^{\circ} 611$, de 3 de junio de 2010. Gaceta Oficial Digital, 8 de junio de 2010. Disponível em: <http://www.gacetaoficial.gob.pa/ pdfTemp/26550/27921.pdf>. Acesso em: 27 jan. 2013. 
nos pontos de venda". ${ }^{(38)}$ Em outros países se discute se se deve ou não considerar a exibição como uma forma de publicidade, apesar de existirem estudos que demonstram que a exibição é um estímulo direto ao consumo de produtos de tabaco. ${ }^{(39)}$ Como se viu, com a finalidade de fugir a essa discussão o Brasil autorizou expressamente a exibição de produtos de tabaco nos pontos de venda.

Por outra parte, como exemplo de uma proibição parcial de publicidade e promoção de produtos de tabaco, pode-se citar a Lei n ${ }^{\circ} 26687$ de 2009 da Argentina que, depois de estabelecer uma proibição geral, incorpora, apesar disso, exceções que suavizam essa medida. Continuando, aí vão os artigos correspondentes:

Art. $5^{\circ}$ - Proíbe-se a publicidade, promoção e patrocínio dos produtos elaborados com tabaco, em forma direta ou indireta, através de qualquer meio de de difusão ou comunicação.

Art. $6^{\circ}$ - Excetua-se da proibição estabelecida no artigo anterior a publicidade ou promoção que se realize:

No interior dos lugares de venda ou distribuição de produtos elaborados com tabaco, conforme o que determine a regulamentação da presente lei;

Em publicações comerciais destinadas exclusivamente a pessoas ou instituições que se encontrem envolvidas no negócio do cultivo, fabricação, importação, exportação, distribuição, depósito e venda de produtos elaborados com tabaco;

Através de comunicações diretas a maiores de 18 anos, desde que se tenha obtido seu consentimento prévio e se tenha verificado sua idade. ${ }^{(40)}$

Esse tipo de política de restrição (tanto parcial como total) tem gerado controvérsias judiciais, às quais nos referiremos na parte seguinte. Será considerada por base a decisão tomada pela Corte Constitucional da Colômbia no final de 2010, tendo em conta que discute uma proibição total de publicidade, alcançando o nível mais alto de restrição. Como se viu, esse nível é o único que garante uma efetiva diminuição do impacto das estratégias da indústria tabagista nas taxas de consumo de produtos do tabaco.

\section{DISCUSSÕES JUDICIAIS. O CASO ANTE A CORTE CONSTITUCIONAL DA COLÔMBIA}

Apesar da evidência sobre a efetividade de medidas de proibição total da publicidade, promoção e patrocínio de produtos de tabaco e dos avanços

(38) O decreto executivo $\mathrm{n}^{\circ}$ 611/2010 motivou duas demandas de nulidade no contencioso administrativo, as quais até o momento não têm decisão final.

(39) WAKEFIELD, Melanie, et al. The effect of retail cigarette displays on impulse purchase. Addiction, v. 103, n. 2, p.322-328, 2008.

(40) "Regulación de la publicidad, promoción y consumo de los productos elaborados con tabaco. Deróganse las Leyes $\mathrm{N}^{\circ} 23.344$ y su modificatoria Ley $\mathrm{N}^{\circ} 24.044$ ". Disponível em: <http://www. ligadelconsorcista.org/node/4368>. Acesso em: 27 jan. 2013. 
legislativos de alguns países nessa matéria, o debate jurídico ainda não alcançou um consenso claro sobre esse ponto.

A liberdade de expressão e sua relação com as políticas de controle de tabaco é um tema que ainda não se encontra definido na região e onde não existe um critério jurídico unificado. São muitos os casos que se vinculam a esse tema, como: a obrigação de incluir certas mensagens na etiqueta ${ }^{(41)}$ ou a necessidade de contar com autorização do Ministério da Saúde para poder emitir anúncios de produtos de tabaco. ${ }^{(42)}$ Alguns tribunais abordam a problemática como uma questão de ponderação de direitos, outros fogem desse debate estabelecendo definições mais restritas aos discursos protegidos pela liberdade de expressão e outros nem sequer entram na discussão jurídica. Todas as interpretações que se viu na região até o momento reconheceram a importância de proteger o direito à saúde, mas, apesar disso, algumas decisões tomaram medidas mais efetivas do que outras, quando se trata de controlar a epidemia de tabagismo na região. ${ }^{(43)}$

O principal problema jurídico que a maioria das decisões judiciais analisou é determinar se o discurso comercial é protegido ou não pela liberdade de expressão e, portanto, se a proibição total da publicidade de produtos de tabaco é permitida dentro de suas jurisdições. Essa análise jurídica se faz à luz das obrigações internacionais dos Estados de proteger os direitos humanos.

Embora inicialmente o debate possa ser visto como de teoria jurídica, conforme se explicou anteriormente, as estatísticas demonstram que ele é crucial na batalha para eliminar a epidemia de tabaco que enfrenta a região, ${ }^{(44)}$ dado que a publicidade sempre tem sido ferramenta fundamental usada pela indústria tabagista para aumentar seu consumo e em especial para obter novos clientes. Se bem que a indústria argumenta que o uso da publicidade é nitidamente uma forma de manter sua marca e distinguir-se como superior às outras, na atualidade é de conhecimento público que o maior interesse da indústria não está relacionado com manter sua marca, mas com a intenção de

(41) Sindicato da Indústria do Fumo no Estado do Rio Grande do Sul vs. Agência de Vigilância Sanitária (Anvisa). Tribunal Federal Regional da $4^{a}$. Região. Disponível em: <http://www.tobaccocontrollaws. org/litigation/decisions/br-20090402-sindicato-da-indstria-do-fumo->. Acesso em: 28 jan. 2013.

(42) Philip Morris México S.A. de C.V. vs. México. Corte Suprema de Justiça do México. Disponível em : < http://www.tobaccocontrollaws.org/litigation/decisions/mx-20040519-philip-morris-mxico,-s.a.de-c>. Acesso em : 28 jan. 2013.

(43) Ver: Sentencia C-830/10. (CORTE CONSTITUCIONAL DE COLOMBIA. Disponível em: <http:// www.corteconstitucional.gov.co/relatoria/2010/C-830-10.htm>. Acesso em: 22 jan. 2013); Agência Nacional de Vigilância Sanitária (Anvisa) vs. Philip Morris Brasil Ind. Com. Ltda. Disponível em: $<$ http://www.tobaccocontrollaws.org/litigation/decisions/br-20090923-agncia-nacional-de-vigilncia-s>. Acesso em : 28 jan. 2013, entre outros.

(44) ORGANIZACIÓN PANAMERICANA DE LA SALUD . Informe Sobre Control de Tabaco para la Región de las Américas, 2011. Disponível em: <http://new.paho.org/par/index2.php?option=com docman\&task=doc_view\&gid=358\&ltemid=253>. Acesso em : 28 jan. 2013. 
fazer chegar sua "mensagem" a possíveis novos consumidores, especialmente crianças e jovens ${ }^{(45)}$.

O debate jurídico sobre o nível de proteção legal que os Estados devem oferecer ao discurso comercial tem sido amplo, considerando que suas possíveis aplicações podem ir além da indústria de tabaco. Não obstante, vários defensores das medidas trataram de separar a indústria do tabaco das outras indústrias, argumentando que "o tabaco é o único produto lícito que se for usado como deve ser mata o usuário". ${ }^{46)}$ A indústria do tabaco tentou envolver diferentes indústrias na discussão para defender seus interesses, argumentando que a proteção do discurso comercial deveria interessar a todas as indústrias; no entanto, essa estratégia não deu maiores resultados, pelo menos na região, uma vez que outras indústrias preferem manter-se à distância e não querem ser associadas à indústria do tabaco(47).

Dentro desse debate jurídico na região registraram-se duas posturas legais. A primeira entende a publicidade como um discurso protegido pela liberdade de expressão, à qual podem ser impostas poucas limitações aplicando um critério estrito de razoabilidade. ${ }^{(48)}$ A segunda posição vê a publicidade como um exercício da liberdade comercial para o qual se permitem maiores restrições, incluindo a proibição total. Mais adiante se fará uma análise mais pormenorizada dessa posição.

Dentro dessa segunda postura, um dos casos mais relevantes na América Latina, que analisa esse problema em profundidade, é a sentença C-830 ${ }^{(49)}$ de 2010 da Corte Constitucional da Colômbia. Nesse caso, um cidadão pede à Corte que declare inconstitucionais os arts. 14, 15, 16 e 17 da Lei $n^{\circ} 1335$ de 2009, a lei de controle de tabaco do país. ${ }^{(50)}$

O problema jurídico analisado pela Corte é se a medida legislativa que proíbe a publicidade e promoção de tabaco desconhece as liberdades de empresa e da iniciativa privada - liberdades que, para serem exercidas plenamente, requerem a possibilidade de usar a publicidade e a propaganda a fim de

(45) ORGANIZACIÓN MUNDIAL DE LA SALUD. 10 datos sobre la epidemia de tabaquismo y el control mundial del tabaco, 2011. Disponível em: <http://www.who.int/features/factfiles/tobacco_ epidemic/es/>. Acesso em: 28 jan. 2013.

(46) Apresentação da Procuradora Geral da Austrália, Nicola Roxon, no O'Neill Institute for National and Global Health. (PRESENTATION by the Honorable Nicola Roxon; Attorney General - Australia, 17 Maio 2012. Disponível em: <http://www.law.georgetown.edu/webcast/eventDetail. cfm?event $\mid \mathrm{D}=1758>$. Acesso em: 28 jan. 2013).

(47) Id. Ibid.

(48) Processo de inconstitucionalidade no caso Nobleza Piccardo S.A.I.C. Y F. vs.Provincia de Santa Fé, Sentença 188/2006, Corte Suprema de Justicia de la Nación Argentina.

(49) CORTE CONSTITUCIONAL DE COLOMBIA. Disponível em: <http://www.corteconstitucional. gov.co/relatoria/2010/C-830-10.htm>. Acesso em: 22 jan. 2013.

(50) CONGRESO DE LA REPUBLICA DE COLOMBIA. Ley 1335 de 2009. Diario Oficial No. 47.417, 21 de julio de 2009. Disponível em: <http://www.secretariasenado.gov.co/senado/basedoc/ley/2009/ ley_1335_2009.html>. Acesso em: 28 jan. 2013. 
apresentar e incentivar o consumo de seus produtos e serviços. ${ }^{(51)}$ Essa análise inclui também o direito de receber informação por parte dos consumidores, argumento que tem sido usado frequentemente pela indústria de tabaco ${ }^{(52)}$, para sustentar sua alegação de que suas manifestações devem ser protegidas pela liberdade de expressão, pois não só protege a elas, empresas, mas a população em geral, que tem o direito de receber informação. Como se observa, ao delimitar desse modo o problema jurídico, a própria Corte toma uma posição clara, entendendo o discurso comercial mais vinculado à liberdade de empresa e da iniciativa privada do que à liberdade de expressão.

Para poder determinar se tal proibição da publicidade e promoção de produtos de tabaco ofende ou não a liberdade de expressão, é fundamental entender o papel da publicidade em sua dupla dimensão "de elemento pertencente à liberdade de empresa e aos direitos do consumidor e manifestação, ainda que restrita, da liberdade de expressão".(53) A Corte Constitucional colombiana nesse caso entende:

a propaganda como uma atividade destinada a dar a conhecer ao público um bem ou serviço com o fim de atrair adeptos, compradores, espectadores ou usuários, ou criar simpatizantes, através de qualquer meio de divulgação. Por outro lado, assinalou a publicidade como a propagação de notícias ou anúncios de caráter comercial ou profissional com o propósito antes apontado. ${ }^{(54)}$

Essas definições são elementos fundamentais da decisão da Corte nesse caso; porém, ainda mais importante, fortalecem o argumento da defesa de leis que buscam a total proibição da promoção de produtos do tabaco. Quando se entende a publicidade como um meio que procura obter uma mudança na tendência de consumo e convencer o consumidor quanto à relevância e às vantagens de um produto determinado, vê-se com clareza como a publicidade incide numa prática social determinada. No caso concreto, a publicidade de produtos de tabaco busca incentivar o consumo do tabaco, o que é considerado uma atividade de alto risco, e as atividades que implicam risco devem ser especialmente reguladas pelo Estado. ${ }^{(55)}$

Essa argumentação leva a um conceito interessante que tem um papel-chave na linha de raciocínio da Corte Constitucional da Colômbia. Esse tipo de prática social, juridicamente tolerada, que não está sujeita à promoção

(51) CORTE CONSTITUCIONAL DE COLOMBIA. Disponível em: <http://www.corteconstitucional. gov.co/relatoria/2010/C-830-10.htm>. Acesso em: 22 jan. 2013.

(52) Ver Sentença C-830 de 2010 (CORTE CONSTITUCIONAL DE COLOMBIA. Disponível em: <http://www.corteconstitucional.gov.co/relatoria/2010/C-830-10.htm>. Acesso em: 22 jan. 2013) e Processo de Inconstitucionalidade da Lei $\mathrm{n}^{\circ} 12.546$ por parte da Confederação Nacional da Indústria (CNI) perante o Judiciário brasileiro, decisão final ainda pendente.

(53) CORTE CONSTITUCIONAL DE COLOMBIA. Disponível em: <http://www.corteconstitucional. gov.co/relatoria/2010/C-830-10.htm>. Acesso em: 22 jan. 2013.

(54) Id. Ibid., p. 33.

(55) UPRIMMNY, Rodrigo; CASTILLO, Camilo. Constitutión, democracia y tabaco en Colombia. Bogotá: Centro de Estudios de Derechos, Justicia y Sociedad (DeJusticia), 2009. p. 10. 
estatal, mas, inclusive, ao seu desencorajamento, configura o que se denomina "mercado passivo"(56). Esse conceito supõe a existência correlativa da autorização para a produção e comercialização de determinado bem ou serviço, como o tabaco, e a fixação de políticas destinadas a desencorajar seu consumo, como a proibição total da publicidade ${ }^{(57)}$. A esse respeito a Corte Constitucional da Colômbia determina que:

é necessário ter em conta que existem ocupações ou transações econômicas que um legislador democrático pode considerar danosas socialmente e que pode, portanto, julgar que devem ser limitadas. (...) Em casos como esses, a sociedade democrática pode assumir a opção de criar o que alguns estudiosos denominam um "mercado passivo", isto é, a atividade é tolerada, uma vez que é legal, mas não pode ser promovida, e assim toda propaganda não é apenas proibida ou fortemente restringida, como também as autoridades promovem campanhas publicitárias contra essas atividades ${ }^{(58)}$.

Assim também entender que o objetivo da publicidade não é informar, mas simplesmente modificar os gostos do consumidor para que prefira um produto dentro de um dado mercado(59), tal como antes se demonstrou, permite aos Estados impor limitações mais restrititvas. Estas limitações são permissíveis na medida em que se entende a publicidade como um exercício da liberdade econômica e comercial e permite a aplicação de um teste de razoabilidade mais leve. Em sentido contrário, seriam muito diferentes as limitações que poderiam ser impostas se a publicidade fosse entendida como um meio cuja única finalidade é transmitir uma mensagem ou informação.

Da mesma forma pode-se analisar o direito dos consumidores de receber informações. A mensagem transmitida pela publicidade não conta com os requisitos necessários para se considerar informação, pois carece de condições de imparcialidade e transparência na apresentação dos dados ${ }^{(60)}$ e por isso não tem o mesmo nível de proteção legal de uma mensagem que se considere informativa. Entretanto, isso não quer dizer que a publicidade comercial, como discurso, não esteja protegida, mas que seu grau de proteção permite ao legislador impor maiores restrições do que aquelas que poderia estabelecer num discurso não comercial.

O que permite distanciar o discurso publicitário de outro tipo de discurso é a intenção do primeiro de influenciar o potencial consumidor e entender que este discurso é uma faculdade dada pela liberdade comercial e não pela liberdade de expressão. Basta analisar o discurso publicitário dentro desses parâmetros para se poder concluir que ele permite maiores restrições do que aquelas que

(56)CORTECONSTITUCIONALDECOLOMBIA.p. 41. Disponível em:<http://www.corteconstitucional. gov.co/relatoria/2010/C-830-10.htm>. Acesso em: 22 jan. 2013.

(57) Id. Ibid., p. 42.

(58) Id., loc. cit.

(59) Id. Ibid.

(60) Id. Ibid. 
em geral poderiam ser estabelecidas para discursos protegidos pela liberdade de expressão. Entende-se que:

A liberdade de opinião e a liberdade de expressão são condições indispensáveis para o pleno desenvolvimento da pessoa. São fundamentais para toda sociedade e constituem a pedra angular de todas as sociedades livres e democráticas. Ambas as liberdades estão estreitamente relacionadas entre si, dado que a liberdade de expressão constitui o meio para trocar e formular opiniões.

A liberdade de expressão é uma condição necessária para consecução dos princípios de transparência e prestação de contas, que, por sua vez, são essenciais para a promoção e proteção dos direitos humanos. ${ }^{(61)}$

Nessa perspectiva, a publicidade está mais relacionada com a liberdade econômica do que com a liberdade de expressão, o que permite maior intervenção estatal. ${ }^{\left({ }^{62}\right)}$ Essa afirmação tem mais força considerando-se que, nesse caso, a intervenção estatal está fundamentada na proteção dos direitos à saúde e à vida, tanto de fumantes como de não fumantes, e que a total proibição da propaganda do tabaco é a medida menos restritiva que permite diminuir, de maneira efetiva, os níveis de consumo de produtos de tabaco e promover a saúde pública. Mais ainda, essa posição encontra uma justificativa adicional, quando se considera que esse tipo de política restritiva de publicidade de produtos de tabaco é complementada por outras que tendem a assegurar que os potenciais consumidores tenham acesso à informação verdadeira e objetiva sobre as características do produto em questão. ${ }^{(63)}$

Essa análise legal por parte da Corte Constitucional da Colômbia não só está abrigada pelos tratados internacionais de direitos humanos, mas, além disso, dentro das obrigações estabelecidas pela CQCT. Apesar disso, essa não é a posição predominante no mundo ou na região, mesmo sendo a posição mais protetora do direito à saúde e a que mais limita as ferramentas da indústria para expandir sua clientela.

Alguns outros tribunais da região fazem uma análise legal dando mais força à ponderação de direitos do que à definição de publicidade e do discurso publicitário. Em ambos os enfoques existe uma ponderação de direitos, mas, apesar disso, a aplicação da análise jurídica se modifica ao se entender o discurso comercial como um discurso protegido pela liberdade de expressão ou, pelo contrário, como um discurso circunscrito ao âmbito das liberdades comerciais. Em função disso, há tribunais que aplicam um critério estrito porque entendem que em princípio não se devem estabelecer restrições à liberdade de expressão. Nesse sentido se poderia,

(61) COMITÉ DE DERECHOS HUMANOS DE NACIONES UNIDAS. Observación General N 34 , Ginebra, 11 a 29 de julio de 2011. CCPR/C/GC/34 (102 ${ }^{\circ}$ período de sesiones).

(62) CORTE CONSTITUCIONAL DE COLOMBIA. Disponível em: <http://www.corteconstitucional. gov.co/relatoria/2010/C-830-10.htm>. Acesso em: 22 jan. 2013.

(63) A CQCT inclui medidas que tendem a assegurar o acesso à informação verdadeira e objetiva sobre as características dos produtos de tabaco, como as advertências sanitárias (Art. 11) e as medidas relativas à regulamentação da divulgação de informação sobre os produtos de tabaco (Art. 10). 
inclusive, seguir estritamente a Convenção Americana de Direitos Humanos que outorga um nível máximo de proteção à liberdade de expressão. Esse tratado, além de fazer referência à liberdade de expressão no Art. 13, pormenoriza o alto nível de proteção reconhecido ao estabelecer o seguinte:

O exercício do direito previsto no inciso precedente não pode estar sujeito à censura prévia, mas a responsabilidades ulteriores, que devem ser expressamente previstas em lei e que se façam necessárias para assegurar:

a) o respeito dos direitos e da reputação das demais pessoas;

b) a proteção da segurança nacional, da ordem pública, ou da saúde ou da moral públicas. ${ }^{(64)}$

Em sentido contrário, e como se viu antes, outros tribunais aplicam um critério mais leve ao conceber o discurso comercial como parte da liberdade comercial e não da liberdade de expressão. Essa última posição permite uma proteção mais efetiva do direito à saúde de fumantes e não fumantes, com o que se cumpre uma obrigação assumida por todos aqueles Países-Partes do Pidesc ou aqueles que incorporam o direito à saúde a suas ordens constitucionais.

Quando se entende que o discurso comercial está protegido pela liberdade de expressão, a proibição total da publicidade e promoção de produtos de tabaco também poderia ser juridicamente viável, embora, sem dúvida, seja de mais difícil justificação. Nesse caso, a ponderação de direitos funciona da seguinte forma: entende-se que a liberdade de expressão protege o discurso comercial, mas, apesar disso, aceita-se que esse direito não é absoluto e, portanto, aceita limitações, as quais devem observar critérios de proporcionalidade e racionabilidade. A proporcionalidade analisa em que razão a medida em questão limita ou afeta um direito determinado, ou seja, se sua afetação é leve ou chega ao ponto de quase anular esse direito, e analisa como essa afetação permite a realização de outro direito. Em função disso, determina-se se existe proporcionalidade na medida. ${ }^{(65)}$ Por outro lado, a razoabilidade analisa a finalidade da medida e sua relação com os deveres de garantia e cumprimento dos fins do Estado.

Quando se trata do direito à liberdade de expressão, a análise que a maioria dos tribunais tem feito é rigorosa, por causa do nível de proteção que os Estados devem assegurar a esta liberdade. A Corte Constitucional colombiana usa frequentemente esse critério e entende que:

No critério rigoroso de razoabilidade os elementos de análise da constitucionalidade são os mais exigentes, conforme, em suas aplicações, o fim da medida deve ser legítimo e importante, mas, além disso, imperioso, e o meio escolhido deve ser não

(64) Art.13.2. (ORGANIZAÇÃO DOS ESTADOS AMERICANOS. Convenção Americana de Direitos Humanos (Pacto de San José). Disponível em: <http://www.pge.sp.gov.br/centrodeestudos/ bibliotecavirtual/instrumentos/sanjose.htm>. Acesso em: 28 jan. 2013).

(65) CORTE CONSTITUCIONAL DE COLOMBIA. Disponível em: <http://www.corteconstitucional. gov.co/relatoria/2010/C-830-10.htm>. Acesso em: 22 jan. 2013. 
só adequado e efetivamente operante, mas, além disso, necessário, ou seja, que não possa ser substituído por um meio alternativo menos lesivo. Adicionalmente, no critério estrito se inclui, como quarto passo, a aplicação de um juízo de proporcionalidade em sentido estrito, de acordo com o qual os benefícios da adoção da medida devem exceder claramente as restrições impostas por esta sobre outros princípios e valores constitucionais. ${ }^{(66)}$

Essa análise legal de proporcionalidade e razoabilidade tem sido usada para avaliar medidas de controle do tabaco por vários tribunais e por especialistas da região (Brasil, México e Estados Unidos). Assim, por exemplo, no Brasil, a liberdade de expressão protege o discurso comercial, mas não é um direito absoluto e, por isso, aceita restrições. No caso da promoção de produtos de tabaco, essas restrições devem ser elevadas por se entender que a publicidade de tabaco somente busca novos consumidores e que a proteção do direito à saúde deve ser uma prioridade do Estado. ${ }^{(67)}$ Cada país e quase cada litígio tem obtido resultados diferentes, tudo dependendo para quais direitos se outorga maior proteção. Vários dos casos outorgam maior proteção ao discurso comercial; porém, ao mesmo tempo, reconhecem que as medidas de proibição da publicidade de tabaco são proporcionais e razoáveis enquanto busquem proteger a saúde e a vida, tanto de fumantes quanto de não fumantes. ${ }^{(68)}$

Apesar de as análises anteriores mostrarem como - inclusive usando o critério estrito de proporcionalidade - a proibição total de publicidade de tabaco é juridicamente viável, o uso do mesmo critério teve um resultado diferente nos tribunais dos Estados Unidos. Até o momento, nos Estados Unidos se tem vinculado a publicidade de tabaco de maneira indireta com a liberdade de expressão e por isso seus tribunais têm outorgado a ela um alto grau de proteção. ${ }^{(69)}$ Essa posição apresenta vários riscos na luta para eliminar a epidemia de tabaco, principalmente porque esse argumento deixa aberta a possibilidade de que essa indústria use sua principal ferramenta para proteger o consumo: a publicidade de seus produtos. Como se viu no começo deste trabalho, só uma proibição total da publicidade pode assegurar que se atinjam, efetivamente, os objetivos de melhorar a saúde pública diminuindo as taxas de consumo de produtos de tabaco.

(66) CORTE CONSTITUCIONAL DE COLOMBIA. op. cit., p. 5.

(67) SILVA, Virgílio Afonso da. A constitucionalidade da proibição total de publicidade de Cigarros. Aliança de Controle do Tabagismo. Brasil, mar. 2010 e HOMSI, Clarissa Menezes (Coord.). Controle do tabaco e o ordenamento jurídico brasileiro. Rio de Janeiro: Lumen Juris, 2011.

(68) CORTE CONSTITUCIONAL DE COLOMBIA. Disponível em: <http://www.corteconstitucional. gov.co/relatoria/2010/C-830-10.htm>. Acesso em: 22 jan. 2013; Discount Tobacco City \& Lottery Inc et al v. USA et al, U.S. Court of Appeals for the 6th Circuit, No. 10-5235, Mar. 19, 2012; Agência Nacional de Vigilância Sanitária (Anvisa) vs. Philip Morris Brasil Ind. Com. Ltda. Disponível em: <http://www.tobaccocontrollaws.org/litigation/decisions/br-20090923-agncia-nacional-de-vigilncia-s>. Acesso em: 28 jan. 2013; Philip Morris México S.A. de C.V. vs. México. Corte Suprema de Justiça do México. Disponível em: <http://www.tobaccocontrollaws.org/litigation/decisions/mx-20040519-philipmorris-mxico,-s.a.-de-c>. Acesso em : 28 jan. 2013, entre outros.

(69) Discount Tobacco City \& Lottery Inc et al v. USA et al, U.S. Court of Appeals for the 6th Circuit, No. 10-5235, Mar. 19, 2012. 
Apesar de a Corte Constitucional da Colômbia ter usado o critério da proporcionalidade estrita num alto número de casos relacionados com o direito à saúde, como já foi visto, no caso da proibição da publicidade de tabaco a Corte menciona a proporcionalidade e faz a aplicação do critério em sua forma mais leve, enfocando sua discussão legal no fim e no objetivo da publicidade. Essa posição clara limita possíveis futuros desafios, por parte da indústria, a normas que proíbem a publicidade de seus produtos e que são as mais eficientes para proteger a saúde e a vida.

É importante destacar que esse tema continua suscitando ampla discussão, com ações legais em curso em vários países da região, como Argentina, Brasil e Estados Unidos. Mais precisamente, a Seção Constitucional da Corte Suprema da Costa Rica declarou há pouco tempo a constitucionalidade de uma proibição quase total à promoção e à publicidade de produtos de tabaco e estabeleceu que:

Do mesmo modo, deve-se externar com precisão que essa norma tem também fundamento na Convenção-Quadro da Organização Mundial da Saúde (OMS) para o Controle do Tabaco (...). De outro lado, recorde-se o que disse esta Secção sobre o valor e a hierarquia desse tipo de normas, que têm por objetivo proteger direitos fundamentais, como neste caso, em que a finalidade da convenção internacional (veja-se seu Preâmbulo) é proteger a saúde pública:

IV. - Por seu lado, na sentença № 3435-92 e seu aditamento, № 5759-93, esta Seção reconheceu que "os instrumentos de "direito humanos" vigentes na Costa Rica têm não somente um valor igual ao da Constituição Política, mas que, na medida em que outorgam direitos e garantias a pessoas, pairam acima da Constituição". (vide Voto 2313-95 das $16: 18$ hs. de 9 de maio de 1995)...(ver sentença $N^{\circ}$ 2007-03043, das 14:47 hs. de 7 de março de 2007).

Em síntese, a norma questionada não só é juridicamente permitida, mas, além disso, está de acordo com o Direito da Constituição sobre os Direitos Humanos. ${ }^{(70)}$

Essa sentença não só ressalta uma vez mais a proximidade entre a CQCT e os direitos humanos, mas também evidencia como o debate jurídico na região continua. Do mesmo modo, outro tanto se pode dizer com respeito ao âmbito legislativo em que são constantes as discussões sobre os limites da regulamentação da publicidade de tabaco em outros países da região.

\section{CONSIDERAÇÕES FINAIS}

Como se demonstrou neste trabalho, a proibição total de produtos de tabaco gera tensões de direitos. Na região existem diferentes abordagens

(70) Sala Constitucional de la Corte Suprema de Justicia de Costa Rica. Exp: 12-002657-0007-Co Res. N 2012-003918. San José, Mar. 20, 2012. 
jurídicas para analisar estas tensões. Apesar disso, numa perspectiva que busca a proteção dos direitos humanos, a publicidade e a promoção de produtos de tabaco devem ser entendidas como uma manifestação da liberdade econômica e comercial, e não como um discurso protegido pela liberdade de expressão. Essa posição, à luz dos tratados internacionais de direitos humanos, permitirá uma restrição a esse direito, protegendo tanto o direito à liberdade de expressão quanto o direito à saúde e à vida.

Um dos obstáculos enfrentados pela defesa de medidas para a proibição total de promoção e publicidade de produtos de tabaco é a falta de homogeneidade dos critérios jurídicos utilizados para avaliar essas medidas. Na América Latina têm-se verificado nos últimos anos certos avanços na política de controle de tabaco e se ressalta também a crescente conexão que se tem feito dessas políticas com obrigações de direitos humanos. ${ }^{(71)}$ Apesar disso, esses avanços não estão refletidos destacadamente nessa discussão, em que, talvez pela possível vinculação com um direito clássico, como é a liberdade de expressão, não existe um posicionamento claro a favor das medidas mais efetivas de controle do tabaco.

Outro ponto que é necessário ressaltar é que a posição que se adota neste trabalho (na linha da sustentada pela Corte Constitucional da Colômbia) enfrenta uma dificuldade com respeito à adequação prática. Apesar de em nível teórico se poder estabelecer claramente uma diferenciação entre o discurso comercial e outro de caráter informativo, é certo que, na prática, essa tarefa pode ser de muito difícil execução. Essa dificuldade prática poderia levar um tribunal a propor uma postura cuidadosa, que assegure que não será vulnerado nenhum tipo de manifestação potencialmente protegida pela liberdade de expressão. Posições desse tipo poderão ser superadas se as medidas de proibição de publicidade e promoção de tabaco forem acompanhadas por outras que tenham por fim assegurar o adequado fluxo de informações a possíveis consumidores.

Apesar da falta de unificação ou das críticas que podem ser feitas com respeito à interpretação de alguns tribunais sobre a liberdade de expressão, o discurso comercial e a publicidade de produtos de tabaco, em geral, os tribunais da região têm alguns parâmetros de proteção ao direito à saúde e à vida relativamente altos. Como se demonstrou, tribunais de outras regiões unificam o discurso comercial e a liberdade de expressão, a qual se considera praticamente um direito absoluto ou que pelo menos assim tem sido interpretado nas questões de controle do tabaco até o momento.

Como sustentamos anteriormente, entendemos que a partir de uma perspectiva de direitos humanos é viável proibir de maneira total a publicidade e promoção de tabaco, porque consideramos que esse tipo de discurso é um

(71) ORGANIZACIÓN PANAMERICANA DE LA SALUD . Informe Sobre Control de Tabaco para la Región de las Américas, 2011, cit. 
elemento das liberdades comerciais. A dificuldade prática para distinguir os diferentes tipos de discurso não representa um obstáculo insuperável, especialmente em função das particularidades do bem cujo consumo se busca promover. Como foi assinalado em várias das diversas decisões mencionadas, os produtos de tabaco são bens inevitavelmente daninhos à saúde humana $\mathrm{e}$ a epidemia de tabagismo se constituiu numa das principais ameaças à efetiva proteção do direito à saúde. Em conclusão, não só a vinculação da publicidade e promoção com as liberdades comerciais, mas também as características particulares dos produtos de tabaco, justificam a posição altamente restritiva que defendemos neste artigo.

\section{REFERÊNCIAS}

ALIANÇA DE CONTROLE DO TABAGISMO. Convenção-Quadro para Controle do Tabaco. Disponível em: <http://actbr.org.br/pdfs/CQCT.pdf>. Acesso em: 22 jan. 2013.

ALTO COMISSARIADO DE NACIONES UNIDAS PARA LOS DERECHOS HUMANOS. Preguntas frecuentes sobreelo enfoque de derechos humanos en la cooperación para el desarrollo. Nueva York; Ginebra, 2006.

ANDREWS, R. L.; FRANKE, G. R. The determinantes of cigarette consumption: a meta-analiysis. Journal of Public Policy and Marketing, v. 10, n. 1, p. 81-100, 1991.

CABRERA, Oscar A.; GOSTIN, Lawrence O. Human rights and the Framework Convention on Tobacco Control: mutually reinforcing systems. International Journal of Law in Context, v. 7, n. 3, p. 285-303, 2011.

; MADRAZO, Alejandro. Human Rights as a Tool of Tobacco Control in Latin America. Salud Publica de Mexico, v. 52, p. 288-297, 2010.

CESCR. Examen de los informes presentados por los Estados partes de conformidad con los Artículos 16 y 17 del Pacto. Observaciones Finales del Comité de Derechos Económicos, Sociales y Culturales: Brasil, 2009. E/C.12/BRA/CO/2.

Examen de los informes presentados por los Estados partes de conformidad con los Artículos 16 y 17 del Pacto. Observaciones Finales del Comité de Derechos Económicos, Sociales y Culturales: Argentina, 2011. E/C.12/ARG/CO/3.

CHALOUPKA, Frank. Curbing the epidemic. Governments and the economics of tobacco control. Tobacco Control, v. 8, n. 2, p. 196-201, 1999.

COMITÉ DE DERECHOS ECONÔMICOS, SOCIALES Y CULTURALES. Comentario General N ${ }^{\circ}$ 14, Ginebra, 2000, E/C. 12/2000/4 (22 ${ }^{\circ}$ período de sessões).

. Disponível em: <www2.ohchr.org/spanish/bodies/cescr/index.htm>. Acesso em: 27 jan. 2013. 
COMITÉ DE DERECHOS HUMANOS DE NACIONES UNIDAS. Observación General N 34, Ginebra, 11 a 29 de julio de 2011. CCPR/C/GC/34 (102 ${ }^{\circ}$ período de sesiones).

CONVENÇÃO SOBRE A ELIMINAÇÃO DE TODAS AS FORMAS DE DISCRIMINAÇÃO CONTRA A MULHER. Disponível em: <http://www.pge.sp.gov.br/ centrodeestudos/bibliotecavirtual/instrumentos/discrimulher.htm>. Acesso em: 27 jan. 2013.

DIFRANZA, Joseph R. et al. Tobacco promotion and the initiation of tobacco use: assessing the evidence for causality. Pediatrics, v. 117, n. 6, p. e1237-e1248, 2006.

HASTINGS, Gerard; MACFADYEN Lynn. Keep Smiling - No one's going to die. An analysis of internal documents from the tobacco industry's main UK advertising agencies. Clinical and Translational Research Commitee and the Tobacco Control Resource Center. Oct. 2000.

HOMSI, Clarissa Menezes (Coord.). Controle do tabaco e o ordenamento jurídico brasileiro. Rio de Janeiro: Lumen Juris, 2011.

LOPEZ, M. Luisa, et al. Impact of cigarette advertising on smoking behavior in Spanish adolescents as measured using recognition of billboard advertising. European Journal of Public Health, v. 14, n. 4, p. 428-432, 2004.

LOVATO C.; LINN G.; STEAD L. F.; BEST A. Impact of tobacco advertising and promotion on increasing adolescent smoking behaviors. Cohrane Database Syst Rev, n. 4, 2003. CD003439.

MOODIE C.; MACKINTOSH A.M.; BROWN A.; HASTINGS G. Tobacco marketing awareness on youth smoking susceptibility and perceived prevalence before and after an advertising ban. European Journal of Public Health, v. 24, Mar 2008.

ORGANIZAÇÃO DOS ESTADOS AMERICANOS. Convenção Americana de Direitos Humanos (Pacto de San José). Disponível em: <http://www.pge.sp.gov. $\mathrm{br} /$ centrodeestudos/bibliotecavirtual/instrumentos/sanjose.htm>. Acesso em: 28 jan. 2013.

ORGANIZACIÓN MUNDIAL DE LA SALUD. 10 datos sobre la epidemia de tabaquismo y el control mundial del tabaco, 2011. Disponível em: <http://www. who.int/features/factfiles/tobacco_epidemic/es/>. Acesso em: 28 jan. 2013.

Report on the global tobacco epidemic. Warning about the dangers of tobacco, 2011. Disponível em: <http://www.who.int/tobacco/global_report/2011/ exec_summary/en/index.html>. Acesso em: 28 jan. 2013.

ORGANIZACIÓN PANAMERICANA DE LA SALUD . Informe Sobre Control de Tabaco para la Región de las Américas, 2011. Disponível em: <http://new. paho.org/par/index2.php?option=com_docman\&task=doc_view\&gid=358\&ltemid=253 $>$. Acesso em : 28 jan. 2013. 
PACTO INTERNACIONAL DOS DIREITOS ECONÔMICOS, SOCIAIS E CULTURAIS. Disponível em: <http://www.oas.org/dil/port/1966\%20Pacto\%20Internacional\%20sobre\%20os\%20Direitos\%20Econ\%C3\%B3micos,\%20Sociais\%20 e\%20Culturais.pdf>. Acesso em: 27 jan. 2013.

PERUGA, Armando. El Convenio Marco Para el Control del Tabacco: respuesta a la globalización de una epidemia comunicada. Gaceta Sanitaria (online), v. 18, n. 5,p. 343-345,2004. Disponível em: <http//scielo.php ?script=sciarttext\&p id=S0213-9112004000700001\&=iso >. Acesso em: 27 jan. 2013.

PRESENTATION by the Honorable Nicola Roxon; Attorney General - Australia, 17 Maio 2012. Disponível em: <http://www.law.georgetown.edu/webcast/eventDetail.cfm?eventID=1758>. Acesso em: 28 jan. 2013.

SAFFER, H.; CHALOUPKA, F. The effect of tobacco advertising bans on tobacco consumption. Journal of Health Economicas, v. 19, p. 1117-1137, 2000.

SILVA, Virgílio Afonso da. A constitucionalidade da proibição total de publicidade de Cigarros. Aliança de Controle do Tabagismo. Brasil, mar. 2010.

SLATER S.; CHALOUPKA F.; WAKEFIELD M.; JOHNSTON L.; O'MALLEY P. The impact of retail cigarette marketing practices on youth smoking uptake. Archives of Pediatric and Adolescent Medicine, v. 161, n. 5, p. 440-445, 2007.

SOTO MAS, Francisco; XAVIER GARCIA LEON, Francisco. La industria tabaquera y la promoción del tabaquismo entre los menores y jóvenes : una revisión internacional. Gaceta Sanitaria (online), v. 23, n 5, p 448-457, 2009. Disponível em: <htpp://scielo.isciii.es/scielo.php ?script=sciarttext\&pid =S0213-91112009000500016\&lng=es\&nrm=iso >. Acesso em: 27 jan. 2013.

U.S. DEPARTMENT OF HEALTH AND HUMAN SERVICES, NATIONAL INSTITUTES OF HEALTH, NATIONAL CANCER INSTITUTE. The role of the media in promoting and reducing tobacco use. Tobacco Control Monograph $\mathrm{N}^{\circ} \cdot 19$. $\mathrm{NIH}$ Pub No. 07-6242, Bethesda, MD, 2008. Disponivel em: <htpp//cancercontrol. Cancer.gov/tcrb/monographs/19/m19 complete pfd>. Acesso em: 27 jan. 1013.

UNICEF. Convenção sobre os Direitos da Criança. Disponível em: <http://www. unicef.pt/docs/pdf_publicacoes/convencao_direitos_crianca2004.pdf>. Acesso em: 27 jan. 2013.

UPRIMMNY, Rodrigo; CASTILLO, Camilo. Constitutión, democracia y tabaco en Colombia. Bogotá: Centro de Estudios de Derechos, Justicia y Sociedad (DeJusticia), 2009.

WAKEFIELD, Melanie, et al. The effect of retail cigarette displays on impulse purchase. Addiction, v. 103, n. 2, p.322-328, 2008.

WORLD BANK. Curbing the epidemic: governments and the economics of tobacco control. Washington, DC, 1999. 